The following pages constitute the final, accepted and revised manuscript of the article:

Arciszewski, Marcin and Pierzynowski, Stefan and Ekblad, Eva

"Lipopolysaccharide induces cell death in cultured porcine myenteric neurons"

Dig Dis Sci. 2005 Sep;50(9):1661-8.

Publisher: Springer.

Use of alternative location to go to the published version of the article requires journal subscription.

Alternative location: http://dx.doi.org/10.1007/s10620-005-2912-2 


\section{Lipopolysaccharide induces cell death in cultured porcine}

\section{myenteric neurons.}

MARCIN ARCISZEWSKI, PhD, STEFAN PIERZYNOWSKI, PhD and EVA EKBLAD,

$\mathrm{PhD}$

Department of Physiological Sciences, Lund University, Lund, Sweden

\section{Acknowledgements}

This work was supported by the Swedish Medical Research Council (project no 04X-1340602B) and the Påhlsson, Ihre, Julin and Crafoord Foundations.

\section{Correspondence to:}

Dr Eva Ekblad,

Department of Experimental Medical Science,

Section Neuroendocrine Cell Biology, BMC F10,

SE-22184 Lund,

Sweden,

Tel no. 46-46-2220688, fax no. 46-46-2223232,

e-mail: eva.ekblad@mphy.lu.se.

Running head: LPS induces death of myenteric neurons 


\section{ABSTRACT}

Enteric bacteria execute, via lipopolysaccharide (LPS), a pathogenic role in intestinal inflammation. The effects of LPS on survival and neurotransmitter expression in cultured porcine myenteric neurons were investigated.

Myenteric neurons were isolated and cultured for 6 days in medium, in LPS (100 ng/ml) with or without $\alpha$-ketoglutarate or nitric oxide synthase (NOS) inhibitor L-NAME, in $\alpha$ ketoglutarate or in NO donor SNAP. Neuronal survival and expression of vasoactive intestinal peptide (VIP) and NOS were evaluated by immunocytochemistry. Addition of LPS significantly decreased neuronal survival; only $40 \%$ survived, as compared to controls run in parallel. The LPS induced neurotoxic effect was not counteracted by the simultaneous presence of $\alpha$-ketoglutarate or L-NAME. Either SNAP or $\alpha$-ketoglutarate influenced neuronal survival. Culturing, particularly in the presence of LPS, markedly increased the proportion of VIP-immunoreactive neurons; NOS-immunoreactive neurons were unchanged.

The reported LPS-induced neurotoxicity indicates loss of enteric neurons as a consequence of intestinal inflammation.

Key words: enteric neurons; neuronal plasticity; vasoactive intestinal peptide, nitric oxide; $\alpha$ ketoglutarate, lipopolysaccharide 


\section{INTRODUCTION}

Enteric nerves are greatly involved in intestinal inflammation (1). Abdominal pain, nausea, vomiting and diarrhoea can be experienced by patients with acute gastroenteritis. Remission reverses the symptoms but infective gastroenteritis may lead to post-infective irritable bowel syndrome (IBS) (2). Also in inflammatory bowel disease (IBD) the enteric flora is considered an important etiological factor (3).

Bacterial lipopolysaccharide (LPS) is found in plasma of IBD patients (4) and acts, via tolllike receptor 4 activation, as an important trigger of myeloid cells that drive the Th1-type intestinal inflammatory process (5). Experimental studies have shown that LPS causes delayed gastric emptying $(6,7)$, intestinal dysmotility $(7,8)$ and sphincteric dysfunction $(9)$, thus unravelling its interaction with enteric nerves. The precise mechanisms behind these acute LPS-induced motor effects are, however, as yet largely unknown. As is the long-term consequences of LPS exposure to the enteric nerves.

Exposure of LPS to neurons in the central nervous system induces neurodegeneration in vivo as well as in vitro. LPS exerts strong neurodegeneration in substantia nigra and midbrain dopaminergic neurons (10-12) as well as in hippocampal (13) and cortical neurons (14). The possibility that LPS may cause neuronal cell death also in the enteric nervous system (ENS) has not been explored. If so, it may, at least partly, explain the motor disturbances seen in patients suffering from IBD and IBS.

The LPS-induced cell loss in central neurons has, by some authors been suggested to be mediated via nitric oxide $(13,15)$ while others claim that it is NO-independent $(16)$. 
Neuroprotection by $\alpha$-ketoglutarate in kainic acid-induced brain damage has been demonstrated (17). If $\alpha$-ketoglutarate has a neuroprotective effect on LPS-induced neuronal cell death has not been tested.

Aim of the present study was to evaluate the effects of LPS alone and in combination with $\alpha$ ketoglutarate or the NOS-inhibitor $\mathrm{N}^{\mathrm{G}}$-nitro-L-arginine methylester (L-NAME) on survival of cultured porcine myenteric neurons. The effects of $\alpha$-ketoglutarate and the NO donor sodiumnitroso-N-acetyl-D,L-penicillamine (SNAP) on neuronal survival were also tested. The in vitro system used is devoid of immune cells and was chosen in order to exclude the interference of immune cell-mediated intestinal inflammatory effects caused by the endotoxin LPS. The influence of LPS on the expression of VIP and NOS in myenteric neurons was also studied. This since it is well known that enteric neurons are able to adapt to injury or unfavourable conditions by changing their chemical coding (18).

\section{MATERIALS AND METHODS}

\section{Animals}

Eleven piglets of both sexes, 3-6 weeks (10-15 kg body weight) were used. Animal care was in agreement with the National Institute of Health guide for the care and use of laboratory animals (NIH publications No. 86-23, revised 1996). The Animal Ethics Committee, Lund and Malmö, Sweden approved the procedures. The animals were sedated with metomidatum hydrochloridum (Hypnodil, Janssen Pharmaceutica, Belgium; $15 \mathrm{mg} / \mathrm{kg}$ b.w.) and killed by an overdose of pentobarbital (Pentobarbitalnatrium, Apoteket, Sweden; 30 mg/kg b.w.). Via a 
midline incision of the abdomen a $15 \mathrm{~cm}$ long segment of mid-jejunum was removed and transferred into cold $0.9 \%$ sodium chloride.

\section{Culture of myenteric neurons}

By using a dissecting microscope strips of longitudinal muscles with adherent myenteric ganglia were dissected out, washed $(2 \times 10 \mathrm{~min})$ with $\mathrm{Ca}^{2+}$ and $\mathrm{Mg}^{2+}$ free Hanks balanced salt solution (HBSS; Gibco BRL, Life Technologies AB, Sweden) and cut with a pair of fine scissors into smaller pieces. The tissue was incubated $\left(2\right.$ hours, $\left.37^{\circ} \mathrm{C}\right)$ in $\mathrm{HBSS}$ with the addition of $1.3 \mathrm{mg} / \mathrm{ml}$ trypsin, $1.5 \mathrm{mg} / \mathrm{ml}$ collagenase type II and $1.5 \mathrm{mg} / \mathrm{ml}$ protease (SigmaAldrich, Sweden). After enzymatic digestion the tissue was mechanically dissociated by trituration using a Pasteur pipette and then three times centrifuged at $1000 \mathrm{rpm}$ in $18^{\circ} \mathrm{C}$. After final centrifugation the pellet was suspended with $5 \mathrm{ml}$ medium containing Neurobasal A (Gibco BRL, Life Technologies AB, Sweden) with the addition of $10 \%$ foetal calf serum, 0.5 nM L-glutamine, $100 \mu 1 / \mathrm{ml}$ streptomycin sulphate and 100 units $/ \mathrm{ml}$ penicillin $\mathrm{G}$ sodium (Gibco BRL, Life Technologies AB, Sweden). Equal volumes $(100 \mu 1)$ of the cell suspension containing myenteric neurons were seeded with $900 \mu 1$ medium on laminin-coated cover glass slides placed in four-well multidishes (Nunclon ${ }^{\mathrm{TM}}$ Surface, Nunc, Denmark). One well contained medium only and this culture served as a parallel control, one contained medium with the addition of $10^{-3} \mathrm{M} \alpha$-ketoglutarate ( $\alpha-\mathrm{KG}$; Sigma-Aldrich, Sweden) or the NOS inhibitor N-nitro-L-arginine methyl ester (L-NAME, $10^{-4} \mathrm{M}$; Sigma-Aldrich, Sweden), one contained medium with the addition of $100 \mathrm{ng} / \mathrm{ml}$ lipopolysaccharide (LPS; E. coli serotype 026:B6, Sigma-Aldrich, Sweden) and one medium with the addition of both LPS (100 ng/ml) and $\alpha$-ketoglutarate $\left(10^{-3} \mathrm{M}\right)$ or L-NAME $\left(10^{-4} \mathrm{M}\right)$. Eight to 10 multidishes were seeded from each pig. The cultures were placed in an incubator $\left(5 \% \mathrm{CO}_{2}\right.$ atmosphere; $\left.37^{\circ} \mathrm{C}\right)$ and kept for 
six days. Medium was changed on the third day of incubation. All procedures were done aseptically. After six days of incubation the cultures of myenteric neurons were fixed (30 minutes) with Stefanini solution containing $2 \%$ formaldehyde and $0.2 \%$ picric acid followed by rinsing (three times, 15 minutes each) with Tyrode solution containing $10 \%$ sucrose. The cultures were then frozen until being processed for immunocytochemistry. In a separate set of experiments the effect of the NO-donor sodium-nitroso-N-acetyl-D,L-penicillamine (SNAP, $10^{-4} \mathrm{M}$; Sigma-Aldrich, Sweden) on neuronal survival was tested.

In order to establish the numbers of neurons seeded $100 \mu 1$ of the cell suspension was placed onto glass slides. At least two such slides were performed from each piglet and denoted 0 days in vitro. The slides were dried $\left(30 \mathrm{~min}\right.$ in $\left.37^{\circ} \mathrm{C}\right)$ followed by fixation and rinsing as described above and processed for immunocytochemistry.

\section{Cryostat sections}

Specimens of the mid-jejunum, 1-2 cm long were dissected out, opened longitudinally, pinned onto a piece of balsa wood with the serosal surface up and placed in Stefanini solution for overnight fixation. Next, the tissue samples were thoroughly rinsed in Tyrode solution containing $10 \%$ sucrose. The specimens were embedded in O.C.T. compound and frozen on dry ice. Longitudinal and transverse cryostat sections of $12 \mu \mathrm{m}$ thickness were cut. Every fifth section was placed on glass slides (SuperFrost ${ }^{\circledR}$ Plus, Menzel GmbH \& CoKG, Germany) and processed for immunocytochemistry in order to study the in vivo conditions.

\section{Immunocytochemistry}

The cryostat sections and the cover glass slides with cultured myenteric neurons were rinsed with $0.1 \mathrm{M}$ phosphate buffer saline (PBS; $\mathrm{pH}=7.4$ ) containing $0.25 \%$ Triton X-100 (Sigma- 
Aldrich, Sweden). Primary mouse monoclonal antibodies against HuC/D proteins (code no A21271, dilution 1:400; Molecular Probes, USA) were used as a general marker for neuronal cell bodies (19). In order to establish the percentages of VIP- and NOS-immunoreactive neurons in cryostat sections and neuronal cultures double labelling studies using monoclonal $\mathrm{Hu}$ antibodies in combination with previously characterised antibodies raised in rabbit against VIP (code no. 7852, 1:1260; Euro-Diagnostica AB, Malmö, Sweden) (20) or NOS (code no. 9223, 1:2560; Euro-Diagnostica AB, Malmö, Sweden) (20) were performed. The slides were incubated overnight $\left(4^{\circ} \mathrm{C}\right)$ in a mixture of primary antisera raised in different species followed by rinsing in PBS. For visualisation of the primary antibody-antigen complexes the slides were incubated for 1 hour in room temperature with a mixture of fluorescein isothiocyanate (FITC)-conjugated goat anti-mouse IgG (1:100; Jackson Immunoresearch, USA) and Texas Red (TR)-conjugated donkey anti-rabbit IgG (1:400; Jackson Immunoresearch, USA). The slides were mounted with phosphate buffered glycerol $(\mathrm{pH}=7.4)$ and viewed with an epifluorescent microscope equipped with filters proper for FITC (494 nm) and TR (595 nm). In addition, the presence in the cultures of glia and smooth muscle cells was studied using mouse monoclonal antibodies against smooth muscle $\alpha$-actin (code A-25472, 1:800; Sigma, St Louis, MO, USA; 19) and rabbit antibodies against glial fibrillary acidic protein (GFAP; code PGF, 1:1280; Euro-Diagnostica AB, Malmö, Sweden) (19).

For controls, antisera (with the exceptions of the $\mathrm{HuC} / \mathrm{D}$ and the smooth muscle actin antibodies) that had been inactivated by the addition of an excess amount of antigen (10-100 $\mu \mathrm{g}$ of synthetic substances per ml diluted antiserum) were used. The HuC/D antibodies recognise the neuronal proteins $\mathrm{HuC}, \mathrm{HuD}$ and $\mathrm{Hel}-\mathrm{N} 1$, all Elav family members, and the smooth muscle actin antibodies recognise the $\alpha$-smooth muscle isoform of actin (42 kD) (19). 
Antigens for performing absorption controls are not available for these latter antisera.

Omission of the primary antibodies abolished immunostaining.

\section{Cell counting and statistical analysis}

Immunocytochemically labelled neuronal cells were counted and their numbers were expressed in percentages as mean \pm S.D. The numbers of surviving neurons after the various treatments were calculated and expressed in percentage of the control run in parallel. The mean from 3 slides from each animal ( $n=3-5$ in each group) was determined.

The proportions of neurons labelled for VIP or NOS were estimated by cell counting on preparations (cryostat sections and cultured neurons) double immunostained with anti-Hu. The following protocol was used for the cover slips with cultured neurons: starting from one defined point of the preparation and moving across the slide in a systematic way, at least 100 Hu-immunoreactive nerve cell bodies were examined. In cryostat sections the myenteric ganglia were identified and at least 100 neurons examined. The proportions of $\mathrm{Hu}-$ immunoreactive neurons also containing VIP or NOS were determined and expressed in percentage of the Hu-immunoreactive cells. The mean from 3 slides from each animal $(n=5$ in each group) was determined.

Statistical differences were determined using one-way analysis of variance test (ANOVA) followed by Bonferroni's post hoc test and $\mathrm{p}<0.05$ was considered statistically significant. 


\section{RESULTS}

\section{Cultured myenteric neurons}

Of the originally seeded myenteric neurons ( 0 days in vitro) approximately half $(53.7 \pm 2.7 \%)$ were present after six days in culture in medium (Neurobasal A, supplemented as described above, but without any pharmacological test substances). Morphological appearance of the neuronal cell bodies after six days in culture differed from that of the 0 days in vitro control. At 0 days in culture the myenteric neurons were round to oval without visible processes. After six days in culture the neurons were larger with an irregular shape. The cultured neurons were frequently found to possess VIP- as well as NOS- immunoreactive terminals contacting other neurons thus creating dense nerve fibre networks in the culture dishes (Fig 1). Within the cultures a thin, almost confluent layer of smooth muscle cells was found. Glia were found to make up an extensive and dense network surrounding groups of myenteric neurons thus creating ganglionic-like formations.

\section{Influence of LPS, NO and $\alpha$-ketoglutarate on survival of cultured myenteric neurons}

Myenteric neurons cultured in the presence of LPS (100 ng/ml) displayed a low survival; only $38.6 \pm 9.0 \%(n=8)$ survived, as compared to neurons cultured in medium only ( $\mathrm{n}=8 ;$ Fig 2$)$.

Simultaneous addition of LPS $(100 \mathrm{ng} / \mathrm{ml})$ and $\alpha$-ketoglutarate $\left(10^{-3} \mathrm{M}\right)$ or L-NAME $\left(10^{-4} \mathrm{M}\right)$ also resulted in a low $(39.8 \pm 9.2 ; \mathrm{n}=5$ and $31.6 \pm 8.3 \% ; \mathrm{n}=3$, respectively) neuronal survival. Neurons cultured in the presence of $\alpha$-ketoglutarate $\left(10^{-3} \mathrm{M}\right)$, L-NAME $\left(10^{-4} \mathrm{M}\right)$ or SNAP $\left(10^{-4} \mathrm{M}\right)$ only, displayed no increase or decrease in neuronal survival $(n=3-5)$ as compared to controls run in parallel. The results are summarised in Fig 3. 


\section{VIP and NOS expression in cultured myenteric neurons}

Double staining of cryostat sections from porcine small intestine $(n=5)$ revealed that $19.6 \pm$ $1.1 \%$ of all Hu-immunoreactive myenteric neurons also displayed immunoreactivity to NOS (Fig 1A and B) whereas only a few (less then 1\%) of the $\mathrm{Hu}$-immunoreactive neurons also contained VIP (Fig 1C and D). After six days in culture a dramatic increase in the number of VIP-immunoreactive neurons was observed (Fig $1 \mathrm{G}$ and $\mathrm{H}$ ). Of the neurons cultured in medium only, $10.0 \pm 2.0 \%$ were VIP-immunoreactive $(n=5)$. Notable was that of the neurons cultured in the presence of LPS $19.5 \pm 1.3 \%$ were VIP-immunoreactive $(n=5)$. NOSimmunoreactivity was observed in approximately $20 \%$ of all cultured myenteric neurons (Fig $1 \mathrm{E}$ and F) irrespective of if the neurons were cultured with or without LPS ( $\mathrm{n}=5$ in each group). The results are summarised in Fig 4. 


\section{DISCUSSION}

The present in vitro study on porcine myenteric neurons demonstrates, for the first time, a neurotoxic effect of the bacterial endotoxin LPS on myenteric neurons. A significant reduction in neuronal survival, as compared to controls run in parallel, was noted in neuronal cultures grown in the presence of LPS. This is in accordance with previous reports on central dopaminergic neurons in which an increased neuronal cell death was observed after exposure to LPS $(10,12)$. The LPS-induced neurodegeneration of dopaminergic neurons was attenuated by the addition of NOS inhibitors thus suggesting that nitric oxide (NO) and/or its metabolites play a critical role $(12,15)$. On the other hand, in dopaminergic neuron cultures NO was found not to mediate the cytotoxic action of LPS; this effect was exerted by the release of inflammatory cytokines such as tumour necrosis factor- $\alpha(\mathrm{TNF} \alpha)$ and interleukin-1 $\beta$ (IL-1 $\beta$ ) $(16,21)$. Increased concentrations of inflammatory cytokines, eventually causing selective white matter injury, have also been described after intracerebral injection of LPS $(22,23)$. In the present study on myenteric neurons, equally low neuronal survival rates were found after exposure to LPS alone or when culturing was in LPS supplemented with the NOS-inhibitor LNAME. This strongly indicates that LPS-induced enteric neurodegeneration is NOindependent. This suggestion is further supported by the finding that culturing porcine myenteric neurons in the presence of the NO donor SNAP had no effect on neuronal survival. The mechanisms by which LPS induces neuronal cell death in the myenteric neurons can, at present only be speculated on. Activation of microglia and their release of proinflammatory factors is considered a crucial event in inflammation-induced neurodegeneration in the brain $(15,24-26)$. Due to the expression of GFAP, vimentin and S-100 enteric glia is considered 
akin to astrocytes (for a recent review see 27) but, a small population resembling microglia of the CNS has been identified by electron microscopy (28). Recent evidence implies that enteric glia play important roles in gut homeostasis, particularly in inflammation (27). This can be illustrated by the fulminate hemorrhagic jejunoileitis that follows ablation of GFAP positive enteric glia, as shown in a transgenic mouse model (29). Exposing cultured enteric glia to LPS or proinflammatory cytokines causes an upregulation of GFAP in glia cells (30) further indicating their responsiveness in inflammation. Thus, the question whether the, here presented, LPS induced neuronal cell death is mediated via a direct effect on the myenteric neurons or if it is mediated via activation of enteric glia needs further investigations. Immunocytochemistry revealed that the culturing of porcine myenteric neurons resulted in an increased number of neurons expressing VIP while the proportion of NOS-immunoreactive ones was unchanged. It has previously been reported that a dramatic increase in the number of VIP-, but not of NOS-, expressing rat myenteric neurons occurs in response to culturing (19), axotomy or colchicine treatment (31). This is suggested to be part of a plastic response to neuronal injury e.g. axonal damage and isolation of the neurons $(19,31)$. Notable, in the present study, was that porcine myenteric neurons exposed to LPS displayed a nearly two-fold higher number of VIP expressing neurons as neurons cultured in medium only. This may reflect that the more severe the injury (presence of LPS within the cultures is more detrimental than culturing only) the higher the VIP up-regulation, suggesting that VIP plays a role in neuroprotection against LPS-induced neuronal cell death. Alternatively, it may be due to a selective cell death caused by LPS, sparing the VIP-expressing neurons. The latter suggestion is, however, contradicted by the finding of an unchanged proportion of NOSexpressing neurons within the cultures. The idea that VIP plays an active role in neuronal 
protection is supported by the recent findings that VIP promotes survival of both porcine (32) and rat $(33,34)$ myenteric neurons in culture. In addition, VIP has been reported to promote survival also of cultured sympathetic (35), cerebral cortical (36) and spinal cord (37) neurons. The glutamate precursor $\alpha$-ketoglutarate exerts neuroprotection against cyanide- (38) and sodium nitroprusside- (39) induced toxicity. Kainic acid-induced damage of brain mitochondrial DNA is completely abolished by co-treatment with $\alpha$-ketoglutarate (17). In addition, cultured astrocytes, but not neurons, release $\alpha$-ketoglutarate suggested to play a role in neuronal homeostasis of glutamate and GABA (40). On the basis of these results we tested the possible neuroprotective effect of $\alpha$-ketoglutarate on LPS treated cultures of myenteric neurons. Presence of $\alpha$-ketoglutarate $\left(10^{-3} \mathrm{M}\right)$ was, however, not found to counteract the LPS evoked myenteric neuronal cell death. Further, $\alpha$-ketoglutarate per se did not influence the survival of cultured neurons, as compared to controls run in parallel. Therefore we conclude that, in the ENS, $\alpha$-ketoglutarate does not promote neuronal survival and does not possess any protective effect on LPS-induced cell death.

In conclusion: The bacteriotoxin LPS significantly reduces the number of cultured porcine myenteric neurons. The LPS toxicity is not counteracted by the presence of $\alpha$-ketoglutarate or NOS inhibition. Culturing causes per se an increased expression of VIP; this is further increased by the presence of LPS. The present findings suggest that LPS-induced loss of enteric neurons contributes to the development of intestinal dysfunction in IBD and postinfective IBS. 


\section{REFERENCES}

1. Spiller RC. Role of nerves in enteric infection. Gut 51:759-762, 2002.

2. Neal KR, Barker L, Spiller RC. Prognosis in post-infective irritable bowel syndrome: a six year follow up study. Gut 51:410-413, 2002.

3. Podolsky DK. The current future understanding of inflammatory bowel disease. Best Pract Res Clin Gastroenterol 16:933-943,2002.

4. Amati L, Caradonna L, Leandro G, Magrone T, Minenna M, Faleo G, Pellegrino NM, Jirillo E, Caccavo D. Immune abnormalities and endotoxemia in patients with ulcerative colitis and in their first degree relatives: attempts at neutralizing endotoxinmediated effects. Curr Pharm Des 9:1937-1945, 2003.

5. Kobayashi M, Kweon M-N, Kuwata H, Schreiber RD, Kiyono H, Takeda K, Akira S. Toll-like receptor-dependent production of IL-12p40 causes chronic enterocolitis in myeloid cell-specific stat3-deficient mice. J Clin Invest 111:1297-1308, 2003.

6. Cullen JJ, Caropreso DK, Ephgrave KS. Effect of endotoxin on canine gastrointestinal motility and transit. J Surg Res 58:90-95, 1995.

7. De Winter BY, De Man JG, Seerden TC, Depoortere I, Herman AG, Peeters TL, Pelckmans PA. Effect of ghrelin and growth hormone-releasing peptide 6 on septic ileus in mice. Neurogastroenterol Motil 16:439-446, 2004.

8. Cullen JJ, Caropreso DK, Ephgrave KS, Hemann LL, Hinkhouse MM. The effect of endotoxin on canine jejunal motility and transit. J Surg Res 67:54-57, 1997. 
9. Fan Y-P, Chakder S, Gao F, Rattan S. Inducible and neuronal nitric oxide synthase involvement in lipopolysaccharide-induced sphincteric dysfunction. Am J Physiol 280:G32-42, 2001.

10. Castano A, Herrera AJ, Cano J, Machado A. Lipopolysaccharide intranigral injection induces inflammatory reaction and damage in nigrostratial dopaminergic system. J Neurochem 70:1584-1592, 1998.

11. Herrera AJ, Castano A, Venero JL, Cano J, Machado A. The single intranigral injection of LPS as a new model for studying the selective effects of inflammatory reactions on dopaminergic system. Neurobiol Dis 7:429-447, 2000.

12. Shibata H, Katsuki H, Nishiwaki M, Kume T, Kaneko S. Lipopolysaccharide-induced dopaminergic cell death in rat midbrain slice cultures: role of inducible nitric oxide synthase and protection by indomethacin. J Neurochem 86:1201-1212, 2003.

13. Lee P, Son D, Lee J, Kim YS, Kim H, Kim SY. Excessive production of nitric oxide induces the neuronal cell death in lipopolysaccharide-treated hippocampal slice culture. Neurosci Lett 349:33-36, 2003.

14. Picot L, Chevalier S, Mezghani-Abdelmoula S, Merieau A, Lesouhaitier O, Leroux P, Cazin L, Orange N, Feuilloley MGJ. Cytotoxic effects of the lipopolysaccharide from Pseudomonas fluorescence on neurons and glial cells. Microb Pathogen 35:95-106, 2003.

15. Arimoto T, Bing G. Up-regulation of inducible nitric oxide synthase in the substantia nigra by lipopolysaccharide causes microglial activation and neurodegeneration. Neurobiol Dis 12:35-45, 2003. 
16. Gayle DA, Ling Z, Tong C, Landers T, Lipton JW, Carvey PM. Lipopolysaccharide (LPS)-induced dopamine cell loss in culture: roles of tumor necrosis factor- $\alpha$, interleukin-1 $\beta$, and nitric oxide. Dev Brain Res 133:27-35, 2002.

17. Yamamoto HA, Mohanan PV. Effect of $\alpha$-ketoglutarate and oxaloacetate on brain mitochondrial DNA damage and seizures induced by kainic acid in mice. Toxicol Lett 143:115-122, 2003.

18. Ekblad E, Bauer AJ. Role of vasoactive intestinal peptide and inflammatory mediators in enteric neuronal plasticity. Neurogastroenterol Motil 16 (Suppl.1):123-128, 2004.

19. Lin Z, Sandgren K, Ekblad E. Increased expression of vasoactive intestinal polypeptide in cultured myenteric neurons from adult rat small intestine. Auton Neurosci 107:9-19, 2003.

20. Ekblad E, Sjuve R, Arner A, Sundler F. Enteric neuronal plasticity and a reduced number of intestinal cells of Cajal in hyperthrophic rat ileum. Gut 42:836-844, 1998.

21. Jeohn GK, Kong LY, Wilson B, Hudson P, Hong JS. Synergistic neurotoxic effects of combined treatments with cytokines in murine primary mixed neuron/glia cultures. J Neuroimmunol 85:1-10, 1998.

22. Cai Z, Pang Y, Lin S, Rhodes, PG. Differential roles of tumor necrosis factor- $\alpha$ and interleukin-1 $\beta$ in lipopolysaccharide-induced brain injury in the neonatal rat. Brain Res 975:37-47, 2003.

23. Pang Y, Cai Z, Rhodes PG. Disturbance of oligodendrocyte development, hypomyelination and white matter injury in the neonatal rat brain after intracerebral injection of lipopolysaccharide. Brain Res Dev 140:205-214, 2003. 
24. Gao HM, Jiang J, Wilson B, Zhang W, Hong JS, Liu B. Microglial activationmediated delayed and progressive degeneration of rat nigral dopaminergic neurons: relevance to Parkinson's disease. J Neurochem 81:1285-1297, 2002.

25. Gebicke-Haerter PJ. Microglia in neurodegeneration: Molecular aspects. Microsc Res Tech 54:47-58, 2001.

26. Qin L, Liu Y, Wang T, Wei SJ, Block ML, Wilson B, Liu B, Hong JS. NADPH oxidase mediates lipopolysaccharide-induced neurotoxicity and proinflammatory gene expression in activated microglia. J Biol Chem 279:1415-1421, 2004.

27. Rühl A, Nasser Y, Sharkey KA. Enteric glia. Neurogastroenterol Motil 16 (Suppl. 1):44-49, 2004.

28. Komuro T, Baluk P, Burnstock G. An ultrastructural study of neurons and nonneuronal cells in the myenteric plexus of the rabbit colon. Neuroscience 7:1797-1806, 1982.

29. Bush TG, Savidge TC, Freeman TC, Cox HJ, Campbell EA, Mucke L, Johnson MH, Sofroniew MV. Fulminant jejuno-ileitis following ablation of enteric glia in adult transgenic mice. Cell 93:189-201, 1998.

30. Von Boyen GB, Steinkamp M, Reinshagen M, Schäfer KH, Adler G, Kirsch J. Proinflammatory cytokines increase glial fibrillary acidic protein expression in enteric glia. Gut 53:222-228, 2004.

31. Ekblad E, Mulder H, Sundler F. Vasoactive intestinal peptide expression in enteric neurons is upregulated by both colchicine and axotomy. Regul Peptides 63:113-121, 1996. 
32. Arciszewski MB, Ekblad E. Effects of vasoactive intestinal peptide and galanin on survival of cultured porcine myenteric neurons. Regul Peptides 125:185-192, 2005.

33. Sandgren K, Lin Z, Ekblad E. Differential effects of VIP and PACAP on survival of cultured adult rat myenteric neurons. Regul Peptides 111:211-217, 2003.

34. Sandgren K, Lin Z, Fex-Svenningsen Å, Ekblad E. Vasoactive intestinal peptide and nitric oxide promote survival of adult rat myenteric neurons in culture. J Neurosci Res 72:595-602, 2003.

35. Klimaschewski L, Unsicker K, Heym C. Vasoactive intestinal peptide but not galanin promotes survival of neonatal rat sympathetic neurons and neurite outgrowth of PC12 cells. Neurosci Lett 195:133-136, 1995.

36. Ashur-Fabian O, Perl O, Lilling G, Fridkin M, Gozes I. SNV, a lipophilic superactive VIP analog, acts through cGMP to promote neuronal survival. Peptides 20:629-633, 1999.

37. Brenneman DE, Eiden LE, Siegel RE. Neurotrophic action of VIP on spinal cord cultures. Peptides 6 (Suppl. 2):35-39, 1985.

38. Dulaney MD, Brumley M, Willis JT, Hume AS. Protection against cyanide toxicity by oral alpha-ketoglutarate acid. Vet Hum Toxicol 33:571-575, 1991.

39. Yamamoto HA. Nitroprusside intoxication: protection of alpha-ketoglutarate and thiosulphate. Food Chem Toxicol 30:887-890, 1992.

40. Westergaard N, Sonnewald U, Schousboe A. Release of alpha-ketoglutarate, malate and succinate from cultured astrocytes: possible role in amino acid neurotransmitter homeostasis. Neurosci Lett 176:105-109, 1994. 


\section{LEGENDS TO FIGURES}

Fig 1. Paired micrographs of cryostat sections showing myenteric ganglia from porcine midjejunum (A-D) and dissociated porcine myenteric neurons cultured for 6 days (E-H) subjected to double immunostaining with $\mathrm{HuC} / \mathrm{D}$ and NOS or VIP. Numerous NOS immunoreactive nerve cell bodies are found both in vivo and after culturing while VIP-immunoreactive cell bodies are few in vivo but increase in number after culturing. Arrows indicate myenteric nerve cell bodies double immunostained for HuC/D and NOS or VIP. Magnification x200.

Fig 2. Porcine Hu-immunoreactive myenteric neurons cultured for 6 days in (A) medium and

(B) LPS. The number of surviving neurons was markedly reduced after exposure to LPS. Magnification x200.

Fig 3. Survival of porcine myenteric neurons after exposure to LPS, LPS and alphaketoglutarate, LPS and the NOS inhibitor L-NAME, alpha-ketoglutarate, the NOS inhibitor LNAME, or the NO donor SNAP throughout the 6 days culture period. Data are presented as \% of controls run in parallel; means \pm SD. Exposure to LPS, with or without the addition of alpha-ketoglutarate or L-NAME, caused a significant decrease in neuronal survival vs. parallel controls (cultured in medium only). ${ }^{*} \mathrm{p}<0.05$.

Fig 4. Percentage of Hu-immunoreactive myenteric neurons also immunoreactive to VIP or NOS in cryostat sections (in vivo) and in neurons cultured for 6 days in medium only or in 
medium with the addition of LPS. The proportion of neurons expressing VIP markedly increased during culturing. This was particularly evident in the neuronal cultures exposed to LPS. Means $\pm \mathrm{SD} ;{ }^{*} \mathrm{p}<0.05$ as compared to in vivo; $\# \mathrm{p}<0.05$ as compared to neurons cultured in medium only. 

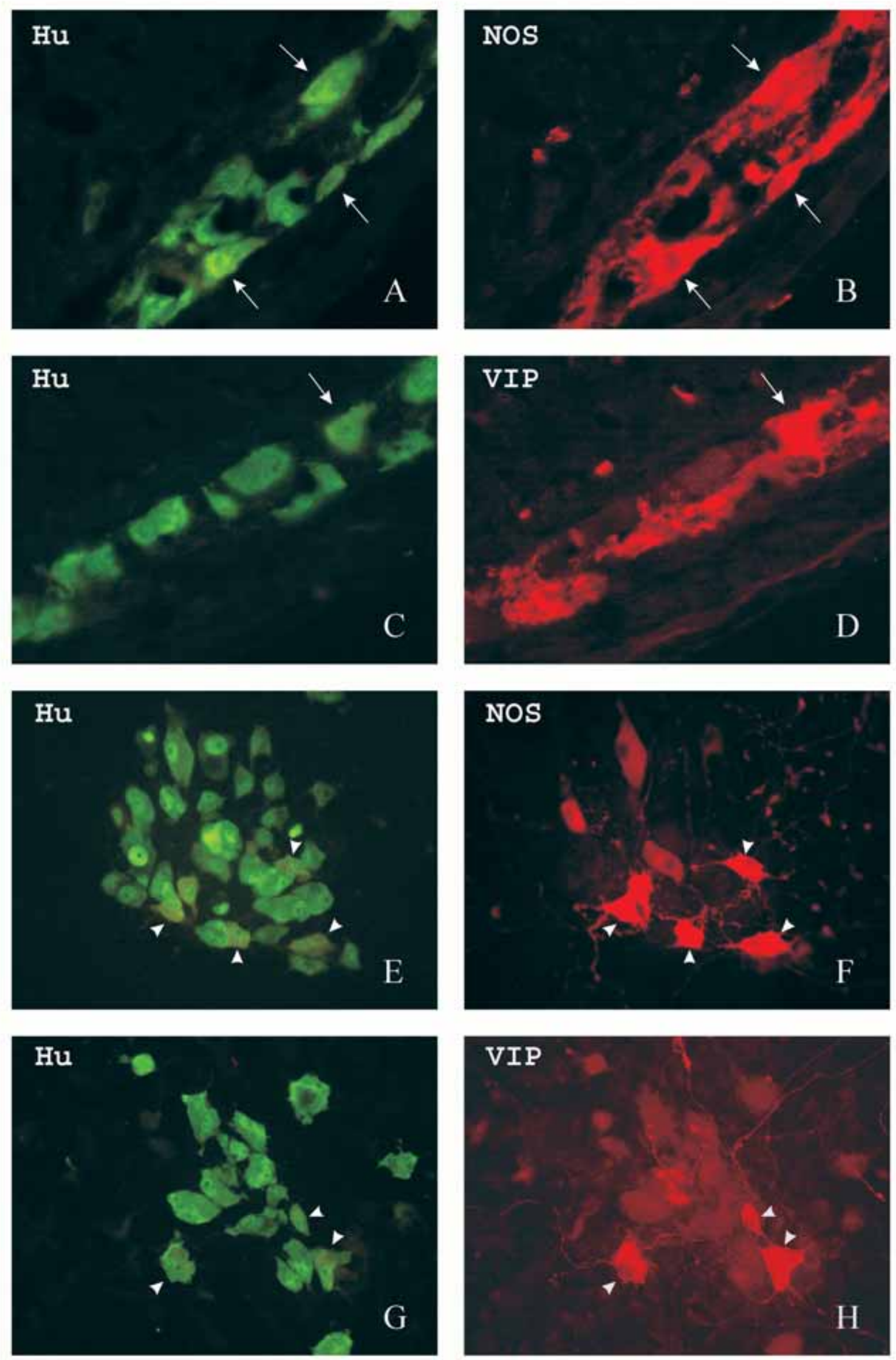


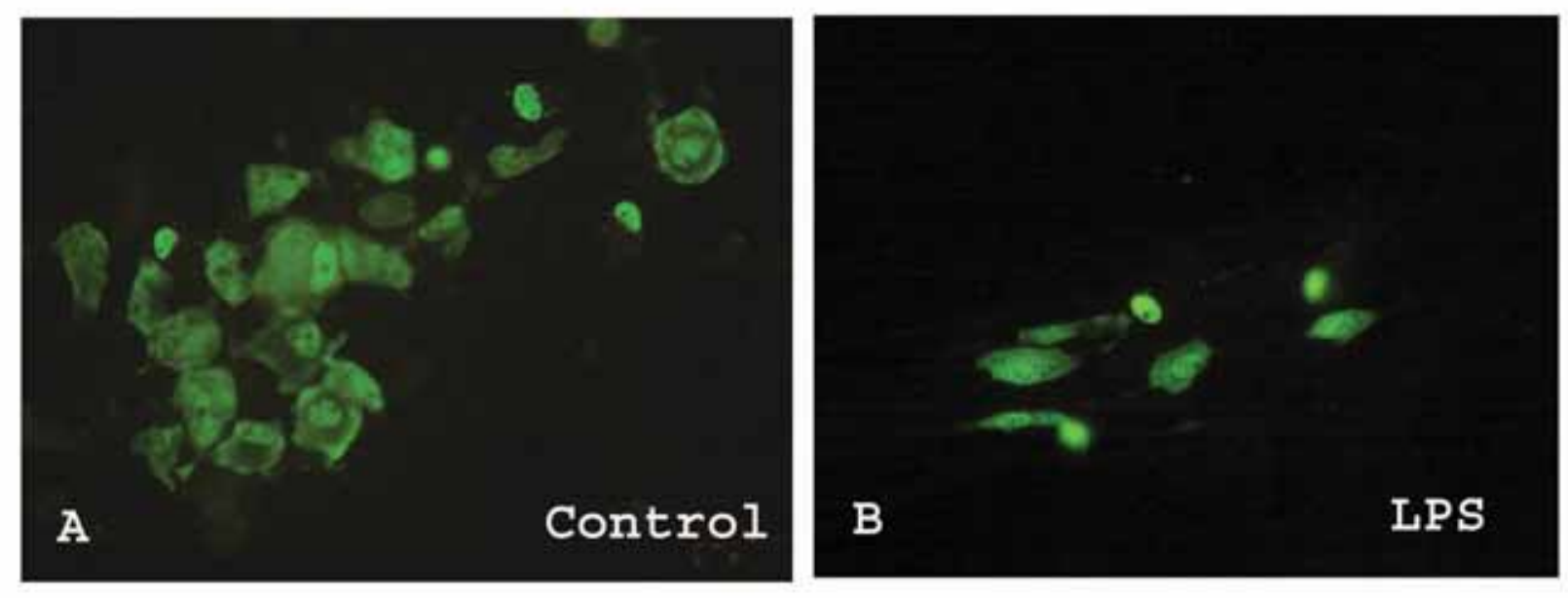




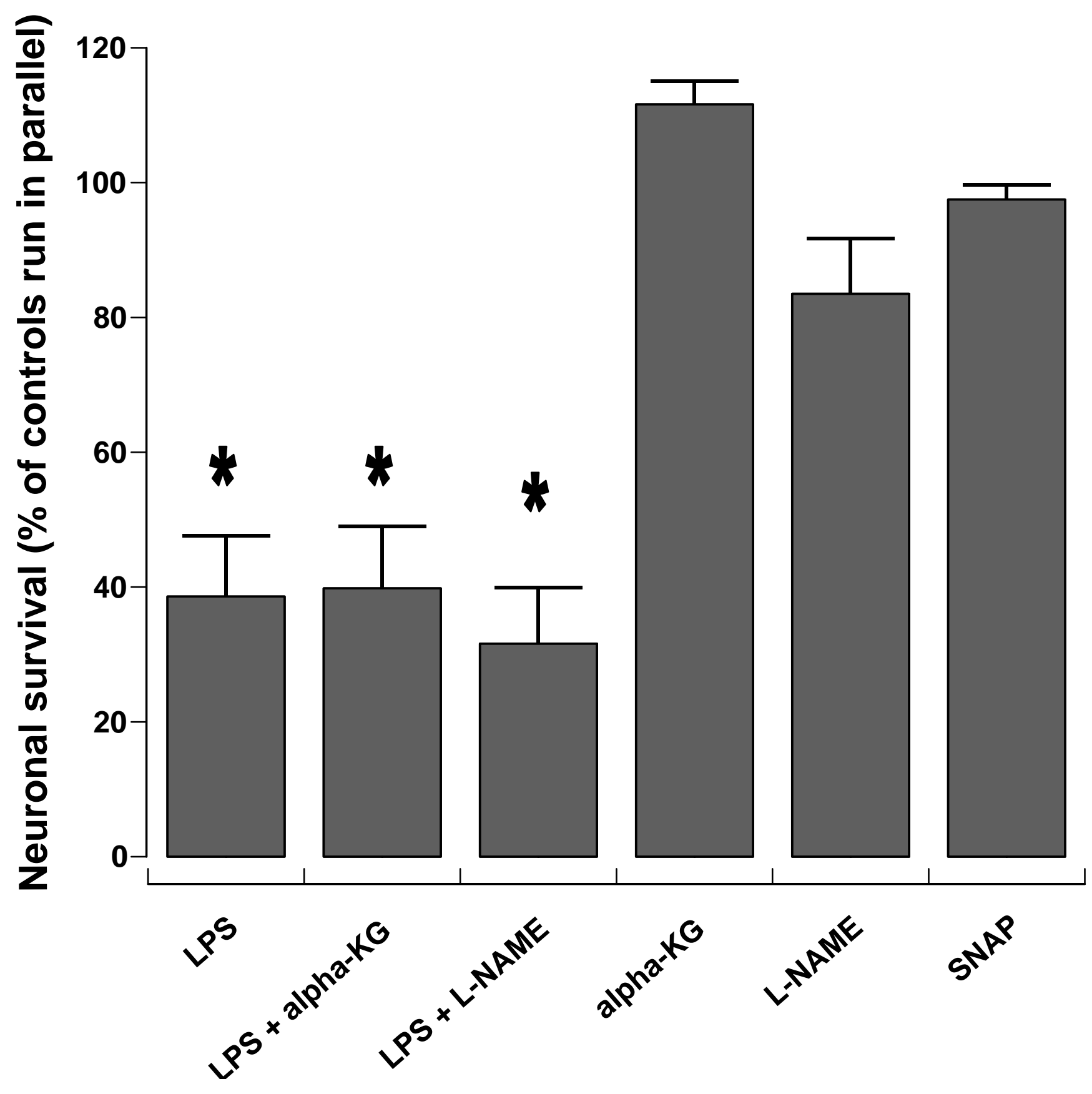

Fig 3 


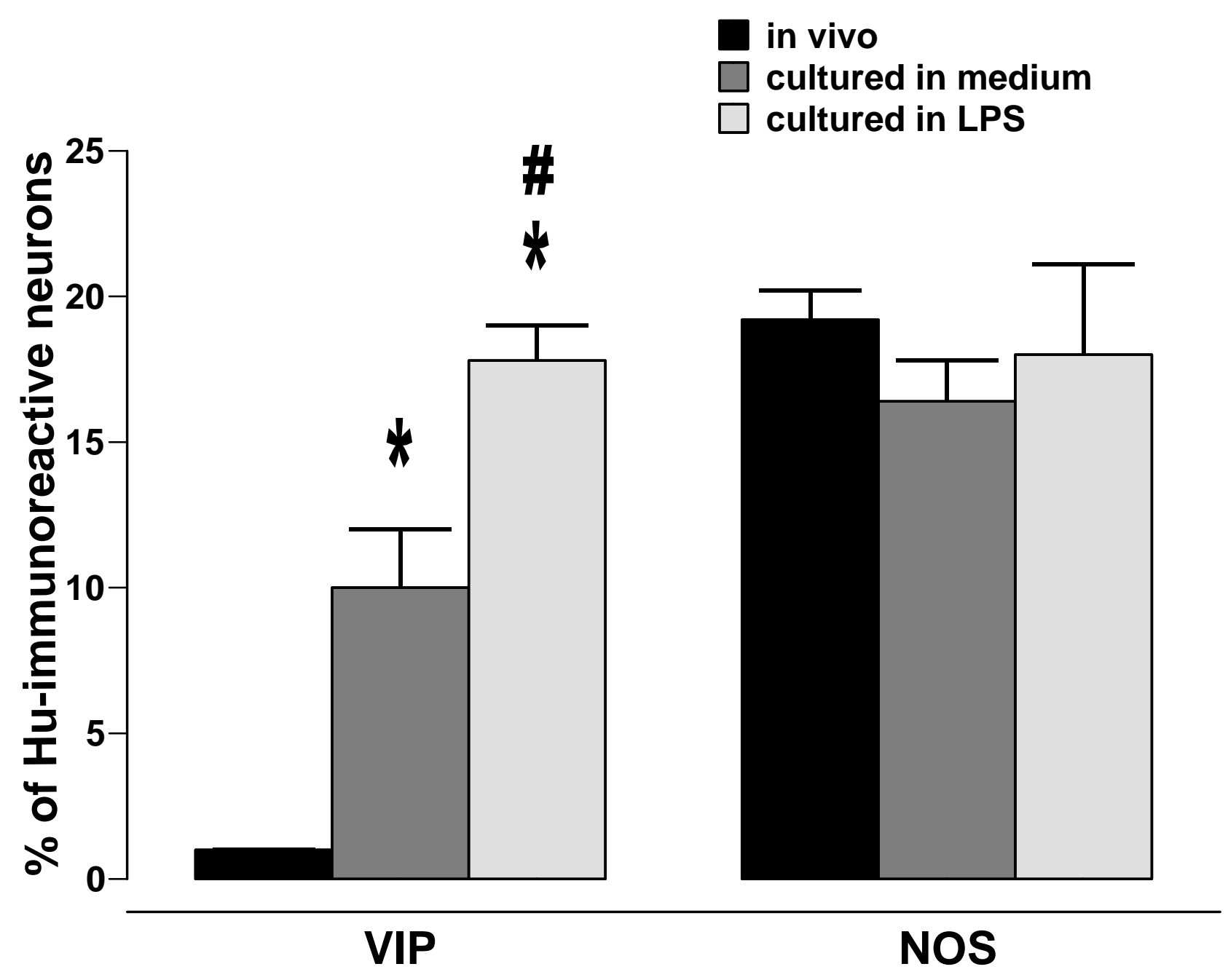

Fig 4 